\title{
La représentation linguistique de différentes cultures à travers une même langue
}

Résumé: L'objectif de notre article est d'étudier l'expression de différentes cultures à travers une même langue. Nous analysons l'œuvre de trois écrivains d'expression française : Assia Djebar, d'origine algérienne, Tahar Ben Jelloun, d'origine marocaine et Andreï Makine, d'origine russe. Ces écrivains ont en commun le français comme langue d'écriture mais leur œuvre, à chacun d'eux, représente une culture différente. Aussi nous interrogeons-nous sur le rapport, chez ces écrivains, entre l'exil dans la langue et l'exil sur le territoire, pour voir comment ces deux types d'exil influent sur la langue de leur écriture pour créer la spécificité de leur style, conditionnée par le fait que ces écrivains reviennent souvent à leur langue maternelle, entraînant de ce fait une cohabitation linguistique. Nous étudions également les changements subis par le français à la suite de cette cohabitation.

Mots clés: Langue, culture, cohabitation linguistique, identité linguistique, identité littéraire

\section{Introduction}

Notre article porte sur les écrivains d'écriture française mais représentant différentes aires géographiques et, de ce fait, différentes cultures. Aussi s’avère-t-il que leur langue d'origine - leur langue maternelle - n'est pas la même que leur langue d'écriture, phénomène que l'on appelle « exil dans une autre langue ».

Nous analysons dans cette optique l'œuvre de trois écrivains d'expression française : Assia Djebar, d'origine algérienne, Tahar Ben Jelloun, d'origine marocaine et Andreï Makine, d'origine russe. Ces écrivains ont en commun le français comme langue d'écriture, mais leur œuvre, pour chacun d'eux, représente une culture différente. Par conséquent, ce qui nous intéresse, c'est d'étudier comment la même langue sert à exprimer différentes cultures et comment ces différentes cultures influent sur la langue, le style et le contenu des œuvres de ces écrivains, par quels moyens linguistiques ces différentes cultures sont exprimées dans leur écriture et comment les deux cultures cohabitent dans leurs œuvres. Que se passet-il lorsque ces écrivains, après avoir choisi, pour des raisons diverses, le français comme langue d'écriture, reviennent à la langue de leur mère et comment cette cohabitation linguistique, culturelle et littéraire détermine-t-elle la spécificité de 
leur écriture ? Quelle est l'influence de la culture d'origine qui se manifeste de différentes façons dans leur écriture, et quels sont les changements que le français subit en traversant trois frontières différentes tout en se retrouvant dans des contextes socioculturels variés ${ }^{1}$ ?

\section{Langue, culture, exil, identité linguistique, identité littéraire}

Si l'on accepte l'idée communément partagée selon laquelle le peuple s'identifie à la langue qu'il parle, la langue étant de ce fait l'un des outils de la construction nationale, de l'identité nationale, on peut se demander pour quelles raisons ces écrivains ont choisi le français, langue étrangère, comme langue de leur écriture, ce qui entraîne, forcément, le changement de leur identité linguistique (ils deviennent bilingues à la suite de leur socialisation par le biais de la langue étrangère). À quel point ce dernier aspect entraîne-t-il à son tour un changement de leur identité d'origine, si l'on prend en considération cette réflexion d'Assia Djebar, selon laquelle « l'identité n'est pas que de papier, que de sang, mais aussi de langue » (Djebar 1999, 42)?

Dans le cas d’Assia Djebar et de Tahar Ben Jelloun, le français est la langue des colonisateurs, donc une langue dominante, imposée, dans laquelle a eu lieu leur socialisation, tant au niveau scolaire qu'universitaire.

Pour Andreï Makine, qui n’a jamais suivi de formation en français, ni subi le français comme langue de la colonisation, c'est un choix volontaire. « Un drôle de Russe qui se met à écrire en français », dira-t-il dans Le Testament français (Makine 1995, 282).

En même temps, il convient de souligner que ces trois écrivains écrivent non seulement en français, mais qu'ils représentent deux des plus prestigieuses institutions culturelles françaises. En effet, en 2006, Assia Djebar est reçue à l'Académie française, et en 2016, Andreï Makine, prix Goncourt en 1995 pour son roman Le Testament français, occupe le même fauteuil, vacant à la suite du décès d’Assia Djebar en février 2015 ; quant à Tahar Ben Jelloun, il se voit décerner le

1 Nous avons consacré une vaste étude aux problèmes surgissant dans l'œuvre des écrivains dits « francophones », pour lesquels le français n'est pas la langue maternelle, mais la langue d'écriture, et qui se trouvent de ce fait entre langues et territoires. Notre analyse, partiellement reproduite ici, porte plus particulièrement sur l'œuvre de deux écrivains maghrébins, Assia Djebar et Tahar Ben Jelloun (voir Dokhtourichvili 2017). 
prix Goncourt en 1989, pour devenir en 2008 membre du jury de ce prestigieux prix littéraire français.

Partagés entre langues et territoires, les trois écrivains, parmi tant d'autres écrivains dits "francophones ", seront tout au long de leur carrière professionnelle en quête de leur identité et de leurs origines. Ainsi Assia Djebar dira-t-elle dans son discours de réception à l'Académie française : « le monolinguisme français, institué en Algérie coloniale, tendant à dévaluer nos langues maternelles, nous poussa encore davantage à la quête des origines ».

Ce qui caractérise les trois écrivains d'origines et de cultures différentes, c'est qu'ils se sentent dédoublés, ils déclarent être entre-deux : entre deux langues, entre deux cultures, entre deux identités. Ce sont des romanciers bilingues qui manient deux langues et deux cultures et qui vivent et racontent leur histoire « avec un pied dans chaque culture » (Knorring 2004, 25). « Étrangement, ou plutôt tout à fait logiquement, c'est dans ces moments-là, en me retrouvant entre deux langues, que je crois voir et sentir plus intensément que jamais ", écrit Andreï Makine (1995, 272).

Selon Claire Herly, « [1]e fait de posséder une double culture présente un avantage mais pose aussi comme pour tous les exilés, le problème de l'identité » (Herly 2004, 154). Ainsi, ces écrivains sont porteurs de trois types d'identité : nationale (c'est-à-dire leur identité d'origine), culturelle (plus complexe et composite) et littéraire.

Si l'on accepte la définition la plus courante de « culture $^{2}$ » - « un héritage traditionnel de valeurs, normes, symboles et rituels particuliers, transmis surtout par le processus de socialisation "(Lafontant 1995, 230) -, on devrait se demander comment déterminer la culture de ces trois écrivains qui sont porteurs des valeurs ${ }^{3}$ maghrébines et russes ? Mais partageant l'idée du même auteur que « telle langue peut véhiculer les valeurs de diverses cultures et, inversement, telle culture peut se dire en diverses langues » (Lafontant 1995, 232-233), on peut affirmer d'ores et déjà qu'Assia Djebar, de même que Tahar Ben Jelloun et Andreï Makine, sont porteurs d'au moins deux cultures, celle qui leur est transmise par les traditions, par la langue de leur mère, par leur origine, et celle qu'ils ont acquise à différentes étapes de leur socialisation, cette dernière ayant eu lieu au moins dans deux langues dans le cas d'Assia Djebar et de Tahar Ben Jelloun.

2 Sur un total de plus de 240.

3 Nous entendons par la notion de valeur « ce qui est posé comme vrai, beau, bien, d'un point de vue personnel ou selon les critères d'une société et qui est donné comme un idéal à atteindre, comme quelque chose à défendre » (Larousse en ligne). 
Pour revenir à la question de l'exil, force est de s'interroger également sur le rapport entre langue, culture et territoire. Il n'y a aucun doute que ce rapport est complexe, vu le fait qu'une même langue peut être parlée sur différents territoires et exprimer différentes cultures. Les rapports entre langue et territoire sont moins stricts - on ne peut pas affirmer que l'usage d'une langue se limite à un seul et unique territoire -, de même qu'entre langue et culture, vu le fait qu'on ne peut affirmer non plus qu'une langue exprime une seule et unique culture. Mais les rapports entre culture et territoire sont plus étroits, si l'on admet la définition de la culture adoptée à l'unanimité par l'UNESCO : «La culture, dans son sens le plus large, est considérée comme l'ensemble des traits distinctifs, spirituels et matériels, intellectuels et affectifs, qui caractérisent une société ou un groupe social. Elle englobe, outre les arts et les lettres, les modes de vie, les droits fondamentaux de l'être humain, les systèmes de valeurs, les traditions et les croyances. » (Unesco 1982).

L'analyse de l'œuvre des trois écrivains nous permet d'affirmer que tout en écrivant en français, ils parlent de la société de leur pays d'origine en donnant une importance thématique à leurs œuvres. Pour Tahar Ben Jelloun, ni le territoire où l'on vit, ni la langue dans laquelle on écrit n'ont d'importance. L'essentiel, pour lui, est d'« écrire, travailler, donner le meilleur de soi en disant le pays et la société » (Gontard 2008). Or, parler d'une société, veut dire parler de sa culture, au sens le plus large du terme.

\section{Le rapport des écrivains avec le français - langue de leur écriture -, leur pays d'origine et le pays d'adoption}

Comment ces trois écrivains expriment-ils dans leurs œuvres leur rapport à la langue, en général, au français, en particulier?

La réflexion sur le choix de la langue constitue un point majeur dans deux romans d'Assia Djebar : L'Amour, la fantasia et La Disparition de la langue française. En effet, Assia Djebar y expose son rapport à la langue française et ce besoin qu'elle ressent d'évoquer certaines choses, plutôt les sentiments et émotions, dans la langue qui vient de sa mère. Ce qui nous permet de constater, à la suite de Mireille Calle-Gruber, que chez Assia Djebar, « la parole est double ; l'écriture est seule - française » (Calle-Gruber 2006, 26). On observe la même tendance chez Tahar Ben Jelloun qui, parlant de l'influence de la double culture dans l'écriture (difficulté de cohabitation des deux langues dans l'esprit de l'auteur), affirme qu'il 
a choisi d'écrire en français, mais avoue que parfois, « le mot exact vient en arabe» (Helmy 2015) ${ }^{4}$. Il lui faut alors chercher l'équivalent ou ce qui s'en rapproche le plus en français (cf. Helmy 2015). En même temps, pour Tahar Ben Jelloun, « [f] aire coexister langue maternelle et langue d'écriture, c'est refuser d'être scindé, refuser la coupure entre passé et présent, étranger et français, ancien public et nouveau public, ancienne identité, nouvelle identité. C’est vouloir rester "uni en soi” »(Yefsah 2011).

Le français, pour Assia Djebar, est le « lieu d'habitation poétique ». Il représente pour elle « une sorte de double de tout ce qu' [elle a] pu dire dans [sa] langue du désir » (cité dans Gauvin 1997, 25). Ainsi, le français, tout en étant langue essentielle de leur socialisation, et, ce qui est particulièrement important, langue de leur écriture, est pour les deux écrivains maghrébins " une autre langue », " la langue étrangère », la langue du dehors, tandis que l'arabe est celle de l'intime. Elle serait même, pour Assia Djebar, « langue marâtre », « langue imposée dans le viol autant que dans l'amour » (Djebar 1995a, 242), « langue de mémoire » (Djebar 2003, 251), une langue qu'elle « a volée à l'ennemi », la « langue de l'adversaire d'hier » (Djebar 1995a, 242-243). Pour elle, s'exprimer en français, c'est consentir « à cette bâtardise, au seul métissage que la foi ancestrale ne condamne pas » (Djebar 1995a, 161). Aussi leur écriture est-elle imprégnée des saveurs et de la sonorité arabes ${ }^{5}$.

Quant à Andreï Makine, le français n'est pas pour lui la langue des colonisateurs comme c'est le cas pour les deux écrivains maghrébins. Il n'est pas non plus sa langue maternelle, ni même sa langue d'instruction. C'est dans son roman autobiographique Le Testament français qu'il explique ce que représentent pour lui la langue, en général, et la langue française, en particulier. Ainsi, pour lui, la langue est une «mystérieuse matière, invisible et omniprésente », elle " modèle les hommes, sculpte les objets, ruisselle en vers, rugit dans les rues envahies par les foules » (Makine 1995, 50). Pour ce qui est du français, c'est le « patois domestique [des petits-enfants de Charlotte], leur dialecte familial, leur argot intime » (Ozolina 2004, 47), c'est sa langue « grand-maternelle» (Makine 1995, 244), une langue « qui dit l'indicible » (Makine 1995, 174), une « langue d'étonnement » (Makine 1995, 251).

Avant de quitter la Russie à l'âge de 30 ans, il vit dans deux cultures et dans deux langues grâce à sa grand-mère d'origine française (qui est en fait sa grandmère adoptive, comme nous l'apprenons à la fin du roman), et c'est justement ce qui lui fera dire que le français est pour lui « la langue grand-maternelle ». Alors

4 Et Jacques Derrida de se demander « si on peut aimer, jouir, prier, crever de douleur tout court dans une autre langue » [que sa langue maternelle]. Et ceci « au bord du français uniquement, ni en lui ni hors de lui, sur la ligne introuvable de sa côte » (Derrida 1996, 14).

5 Pour plus de détails, voir Dokhtourichvili (2017). 
qu'il est encore en Russie, bien avant son exil en France, il « se sent entre-deuxlangues », affirmant que le français est " une greffe fabuleuse dans nos cœurs [il s’agit de lui et de sa sœur] ... portant en lui le fruit de toute une civilisation » (Makine 1995, 50).

C'est quand il apprend que Charlotte n'est pas sa grand-mère maternelle, mais sa grand-mère adoptive, qu'il n'a donc aucune origine française, c'est au moment où elle passe au français pour lui raconter l'histoire de sa naissance et de son adoption, que l'idée lui vient d'écrire en français :

Charlotte avait parlé en français. [...] Elle aurait pu parler en russe. Cela n’aurait rien enlevé à l'instant recréé. Donc il existait une langue intermédiaire. Une langue universelle ! Je pensai de nouveau à cet « entre-deux-langues » que j'avais découvert grâce à mon lapsus, à la « langue d'étonnement ». [...] Et c'est ce jour-là, pour la première fois, que cette pensée exaltante me traversa l'esprit : " Et si l'on pouvait exprimer cette langue par écrit ?». (Makine 1995, 251)

Une fois en France, les éditeurs ne voulant pas accepter ses textes écrits directement en français, il invente un traducteur et envoie le manuscrit en le présentant comme traduit du russe. Il est accepté, publié et salué pour la qualité de la traduction. Il se dit alors poursuivi par sa " malédiction franco-russe ». Si, enfant, il « était obligé de dissimuler la greffe française, à présent c'était [sa] russité qui devenait répréhensible » (Makine 1995, 282).

Comme le remarque à juste titre Edward Welch, « il doit négocier un chemin entre deux langues et deux cultures » (Welch 2004, 21). Il comprend qu'il peut se servir du français comme d'un outil, d'une langue littéraire et poétique. De ce fait, « il peut vivre son mouvement entre le français et le russe non pas comme une condamnation, mais comme une opportunité, comme quelque chose qu'il peut exploiter et dont il peut jouir »(Welch 2004, 21).

En même temps, il se rend compte que « cette langue-outil maniée, affûtée, perfectionnée » (Makine 1995, 244) n'était rien d'autre que l'écriture littéraire. Lui qui a toujours cru que le français était sa « langue grand-maternelle », il se rend compte un jour, en découvrant des couples de mots dits trompeurs (tels précepteur/percepteur, décerner/discerner), après avoir commis quelques maladresses verbales tout en se corrigeant lui-même, qu'il a eu une révélation foudroyante : «j'étais en train de parler une langue étrangère ! » (Makine 1995, 243).

Une autre particularité qui distingue Andreï Makine des deux auteurs maghrébins, c'est qu'il « vit la vie française [c'est-à-dire la culture française] dans les livres, la vie russe [c'est-à-dire la culture russe] dans le réel ». " J'avais vécu sans soleil, sans désir - dans le crépuscule des livres. À la recherche d'un pays fantôme, d'un mirage de cette France d'antan peuplée de revenants ... » (Makine 1995, 197). Il dira dans Cette France qu'on oublie d'aimer : « La francité devint pour 
les Russes ce miroir intellectuel, cette altérité de jugement dont toute nation a besoin pour s'affirmer » (Makine 2006, 26). Et c'est le réel qui l'emporte définitivement pour déterminer son identité. C'est ainsi qu'il essaie d' « en finir avec cette France de Charlotte qui avait fait de [lui] un étrange mutant, incapable de vivre dans le monde réel » (Makine 1995, 223), puisque c'est elle « qui [lui] avait transmis cette sensibilité française - la sienne -, [le] condamnant à vivre dans un pénible entre-deux-mondes » (Makine 1995, 224). En se rendant compte du caractère paradoxal de la Russie, il constate : " La Russie, tel un ours après un long hiver, se réveillait en moi. Une Russie impitoyable, belle, absurde, unique. Une Russie opposée au reste du monde par son destin ténébreux » (Makine 1995, 183184). Il comprend qu'être Russe signifie « porter dans son âme tous ces êtres défigurés par la douleur, ces villages carbonisés, ces lacs glacés remplis de cadavres nus » (Makine 1995, 211).

Il va le comprendre vers la fin du livre, lorsqu'il se rend compte que sa « greffe française semblait ne plus exister » (Makine 1995, 195), constatant que l'enfant qui « avait imaginé une ville fabuleuse s'élevant de cet horizon brumeux ... [l'Atlantide française], cet enfant n'était plus », que sa « singularité avait été définitivement dépassée », qu'il « était comme eux [les autres Russes], et en plus, prêt à tout pour expier [sa] marginalité », qu'il « était guéri » (Makine 1995, 200), « qu'il n’avait plus à se débattre entre [ses] identités russe et française », qu'il s'acceptait en tant que Russe (Makine 1995, 237).

Le pénible « entre-deux » se lit dans le passage suivant : «Oui, si, à la mort de mes parents, il m'arriva de pleurer, c'est parce que je me sentis Russe. Et que la greffe française dans mon cœur se mit à me faire, par moments, très mal » (Makine 1995, 184).

Aussi en veut-il à Charlotte de « cette vie très européenne, dans son bon sens et sa propreté, qu'elle menait à Saranza » trouvant « en elle l'Occident personnifié, cet Occident rationnel et froid contre lequel les Russes gardent une rancune inguérissable. [...] La greffe française que je croyais atrophiée était toujours en moi et m'empêchait de voir. " (Makine 1995, 224).

Quelle est donc l'image de la Russie que donne Andrei Makine dans ses romans ? La toute première est celle d'un « énorme empire » :

Autour de nous s'étendait l'énorme empire, puisant un orgueil particulier de l'exploration de ce ciel insondable au-dessus de nos têtes. L'empire avec sa redoutable armée, avec ses brise-glace atomiques éventrant le pôle Nord, avec ses usines qui devaient bientôt produire plus d'acier que tous les pays du monde réunis, avec ses champs de blé qui ondoyaient de la mer Noire jusqu'au Pacifique... Avec cette steppe sans limites. (Makine 1995, 29)

L'image suivante est celle du village russe qui est nécessairement « un chapelet d'isbas (avec au milieu le poêle - son énorme cœur » (Makine 1995, 65), il parle 
des « villages paisibles russes - isbas, puits, haies - plongés dans la brume du grand fleuve » (Makine 1995, 72).

La Russie, c'est le pays de l'« hiver éternel » (Makine 1995, 39). Quant à la Sibérie, elle est « absurde et inévitable comme le destin » (Makine 1995, 66). Une autre image typiquement russe, c'est « [...] le banc des babouchkas, l'institution sans laquelle la cour russe n'est pas pensable» (Makine 1995, 29), «[...] les babouchkas les plus folkloriques, directement sorties des contes - avec leurs châles épais, leurs visages mortellement blêmes, leurs mains osseuses, presque bleues gisant sur les genoux» (Makine 1995, 35).

Il ressent un « indestructible amour envers la Russie » tout en se demandant pourquoi il l'aime : « Ce pays est monstrueux ! Le mal, la torture, la souffrance, l'automutilation sont les passe-temps favoris de ses habitants. Et pourquoi je l'aime ? Je l'aime pour son absurde. Pour ses monstruosités. J'y vois un sens supérieur qu'aucun raisonnement logique ne peut percer ... » (Makine 1995, 186). Il l'aimerait même si « cet amour était un déchirement permanent. Plus la Russie que je découvrais se révélait noire, plus cet attachement devenait violent. Comme si pour l'aimer, il fallait s'arracher les yeux, se boucher les oreilles, s'interdire de penser » (Makine 1995, 186).

Mais surtout, la Russie c'est un pays qui « est ainsi fait. On y entre facilement, mais on n'en sort jamais » (Makine 1995, 82). C'est ainsi qu'il explique pourquoi Charlotte, sa grand-mère adoptive, « cette Française égarée dans l'immensité neigeuse de la Russie », n’a pu retourner en France.

Pourtant, depuis qu'il se trouve en France, loin de son pays, Andreï Makine se crée une autre image de la Russie. Comme le dit Nina Nazarova, « de mauvais souvenirs s'effacent avec le temps, cédant le pas à des souvenirs d'années heureuses et les contours d'une autre Atlantide apparaissent à l'horizon, cette fois russe » (Nazarova 2004, 63).

Pour ce qui est de la France, elle se confondait pour Aliocha et sa sœur avec sa littérature. Enfants, ils découvraient la France « à travers sa vie littéraire, sa matière verbale moulée dans un sonnet et ciselée par un auteur ", pour eux, « c'était un pays livresque par essence, un pays composé de mots, dont les fleuves ruisselaient comme des strophes, dont les femmes pleuraient en alexandrins et les hommes s’affrontaient en sirventès » (Makine 1995, 292).

Mais cette Atlantide française perdra son image fabuleuse, puisqu'une fois arrivé en France, Andreï Makine fait une constatation déroutante : " C’est en France que je faillis oublier définitivement la France de Charlotte » (Makine 1995, 267).

Il mène une conversation imaginaire avec Charlotte en lui disant que « cette littérature-là [adorée par les Russes] était morte en France » (Makine 1995, 267). Et dans cette conversation imaginaire, où il redevient adolescent, il entend Charlotte 
lui parler de l'importance des livres pour les Russes pour lesquels « l'écrivain était un dieu », qu'en Russie « on attendait de lui et le Jugement dernier et le royaume des cieux à la fois », que dans ce pays plongé dans la misère, « le livre n’avait pas de prix ! », que là-bas, " on pouvait ne pas acheter une paire de chaussures et se geler les pieds en hiver, mais on achetait un livre » (Makine 1995, 293).

Tout comme dans les textes d'Assia Djebar et de Tahar Ben Jelloun rédigés en français, où l'on entend l'arabe en les lisant, dans les textes d'Andreï Makine, c'est l'âme, la langue et la culture russes qui sont exprimées à travers et par le français. Parlant de l'originalité des écrivains qui s'expriment dans une autre langue que celle de leur mère, Tahar Ben Jelloun souligne la faculté de la langue qui consiste en ce qu'elle « casse les mots, déchire leur enveloppe et cherche de nouveaux parfums », et ceci à l'insu de l'auteur. Cette langue, pour lui, « n'est ni une "bilangue” ni un "interlecte”. C'est du français qui voyage et qui se laisse séduire par d'autres rivages, d'autres rêves et d'autres exigences ». Selon lui, l'imaginaire des écrivains comme lui « donne l'hospitalité à une langue [au français] qu'il traite avec générosité et plaisir et humour » (Gontard 2008).

Ce nouveau parfum exprimé par deux langues différentes, on le trouve dans cette observation d’Andreï Makine. Le même mot prononcé en russe (Цapъ) et en français (tsar) acquiert pour lui une connotation différente : « quand je prononçais Царъ, dit-il, un tyran cruel se dressait devant moi ; tandis que le mot tsar en français s'emplissait de lumières, de bruits, de vent, d'éclats de lustres, de reflets d'épaules féminines nues, de parfums mélangés - de cet air inimitable de notre Atlantide » (Makine 1995, 59).

Pourquoi Andreï Makine, tout en vivant actuellement en France, continue-t-il toujours à écrire sur la Russie, sur l'Union soviétique ? On peut trouver une réponse à cette question dans son livre intitulé La femme qui attendait, où il dit avoir compris « le paradoxe agaçant de l'art sous un régime totalitaire : La dictature est souvent propice à la tragique naissance des chefs-d’œuvre... » (Makine 2004, 39).

Il nous semble que c'est la nostalgie de ce pays tout en paradoxes qui lui fait écrire des livres dont les sujets sont toujours inspirés par la terre qu'il a quittée.

\section{Le vocabulaire arabe et russe dans les romans des écrivains de langue française}

Comment les cultures arabe et russe sont-elles exprimées en langue française ? Premièrement, par l'apparition des mots arabes et russes - noms d'objets d'usage quotidien, toponymes, patronymes, termes administratifs, religieux ou mili- 
taires -, pour nommer des réalités arabes et russes, parfois avec une explication immédiate en français, parfois en les réutilisant avec les mots français, comme le fait par exemple Berkane, le personnage du roman d'Assia Djebar La disparition de la langue française, en parlant de ses ascendants, avec le mot «Imazighen» dont la signification est donnée dans le cotexte immédiat : « ... ces Imazighen devinrent pourtant nos héros, eux, les corsaires turcs qui avaient écumé la Méditerranée, ces "rois d'Alger" du seizième au dix-huitième siècle ...» (Djebar 2003, 14).

Dans Le Blanc de l'Algérie, parlant de pèlerinage, elle fait dire à un des poètes, Mammeri : «Un petit nombre cherche la sagesse et les beaux dits (ad-awin) » (Djebar 1995b, 155), mettant entre parenthèses et en italiques le dernier syntagme en arabe, trouvant visiblement que son équivalent français ne recouvre pas entièrement le sens qu'elle veut y mettre.

Les caractéristiques spécifiques des personnages sont souvent données dans les deux langues pour souligner selon nous l'importance de cette spécificité de caractère local. Ainsi, c'est dans les deux langues que Berkane explique le retour dans son pays, plutôt, dans sa ville d'origine : « Ma houma, comme il disait. C'est le seul mot arabe que Marise sache prononcer : houma ! Elle a appris à rendre le "h" aspiré ; elle peut même s'exclamer : "Ya ouled el houma!" exactement comme Berkane le disait ! Comme il le dira quand il reviendra : "Ô enfants de mon quartier !” (Djebar 2003, 278).

À la différence des textes d'Assia Djebar, dans les textes de Tahar Ben Jelloun, les mots et les expressions arabes sont plus souvent utilisés, mais on y observe rarement l'utilisation de leurs équivalents français. C'est le contexte qui doit nous aider à saisir leur signification, ou bien le lecteur doit connaître ces phénomènes caractéristiques de la culture maghrébine, comme dans les exemples suivants tirés du recueil de poèmes Les amandiers sont morts de leurs blessures : «Elle lui a proposé de lui passer du rassoul ${ }^{6}$ dans le dos. Elle remplit ses mains de henné parfumé et lui dit : tiens, il vient de la Mecque. » (Ben Jelloun 1976, 45).

Si les dictionnaires de langue française ne connaissent pas le rassoul, ils donnent l'explication du mot moussem, appelé également waada en Algérie, et qui désigne au Maghreb une fête régionale annuelle associée à une célébration religieuse. Ce phénomène doit avoir une grande importance dans la vie des Marocains, puisque l'auteur le reprend plusieurs fois dans le même texte, Les amandiers vont mourir de leurs blessures : «'invente des moussems à profusion» (Ben

6 Dans les textes d'Assia Djebar, la plupart des mots arabes sont en italiques ou placés entre guillemets. Dans les exemples tirés des textes de Tahar Ben Jelloun, c'est nous qui avons mis en italiques tous les mots et expressions arabes. 
Jelloun 1976, 107). « Dans la rue qui s’insinue en spirale/ Et s'arrête au seuil du souvenir emmuré/ De là l'odeur de tes remontrances/ au jour du moussem des moussems. » (ibid., 115).

Pour ce qui est de l'expression de la culture russe, on peut repérer dans Le Testament français d'innombrables mots russes exprimant les objets de la vie quotidienne, les coiffures et vêtements, la nourriture, les termes administratifs ou militaires, les toponymes, les patronymes, etc. La plupart d'entre eux sont déjà intégrés dans le lexique français. Mais pour transmettre d'autres particularités de la culture russe, Andreï Makine utilise dans ce roman un nombre considérable de mots qu'il transcrit en français, en italiques et entre guillemets, tout en donnant leur signification en français.

Dans la deuxième des trois épigraphes, Andreï Makine rapporte la réflexion de Joseph de Maistre tirée des Soirées de Saint-Pétersbourg : « Le Sibérien demandera-t-il au ciel les oliviers, ou le Provençal du klukwa? ». C’est là le tout premier mot russe, désignant un type de baie (la canneberge) que l'auteur ne traduit ni n'explique. Ce qui annonce le dialogue entre deux cultures que nous allons observer tout au long du roman. Par la suite, chaque fois que l'auteur voudra garder la couleur locale ou transmettre son état d'âme en se sentant dédoublé du fait de sa position entre deux langues et deux cultures, il utilisera d'autres mots russes transcrits en français, dont il donnera des équivalents français. Ainsi, il expliquera la signification et l'étymologie du mot derevnia qui vient de dérévo - l'arbre, le bois, écrit-il, tandis qu'il n'a pas besoin d'expliquer le sens du mot « isba », qui fait déjà partie du lexique français à force d'avoir été utilisé par d'autres écrivains français. En effet, lorsque Charlotte, parlant de Marcel Proust, dit à ses petits-enfants qu'on le « voyait jouer au tennis à Neuilly, sur le boulevard Bineau, [...] le village avec ses maisons en bois, son troupeau et son coq » (Makine 1995, 38), ils imaginent « ce dandy aux grands yeux langoureux [jouer au tennis] au milieu des isbas » (ibid., 39).

Quelle influence le français, langue d'écriture des écrivains venus de régions et d'horizons différents, subit-il du fait qu'il n'est pas leur langue d'origine ? Nous avons repéré dans les textes de ces trois auteurs un grand nombre de mots de leur langue maternelle dont la plupart ont enrichi le lexique français en étant fixés dans les dictionnaires. 


\section{Mots d'origine arabe}

Nous les avons regroupés sous différentes rubriques :

Noms de vêtements

Un fez ou encore une chéchia - coiffure tronconique de laine rouge ou blanche, ornée parfois d'un gland ou d'une mèche de soie ou de laine. Burnous - grand manteau de laine à capuchon et sans manches (en usage dans les pays du Maghreb). Haïk - longue pièce d'étoffe rectangulaire dans laquelle les femmes musulmanes se drapent comme dans un manteau par-dessus les autres vêtements. Calicot - toile de coton assez grossière.

\section{Noms de plantes}

Cumin - plante aromatique originaire du Moyen-Orient. Henné - plante du MoyenOrient et de l'Afrique du Nord dont l'écorce et les feuilles séchées et pulvérisées fournissent une poudre colorante jaune ou rouge. Khat (qat) - arbuste d'Abyssinie et du Yémen dont les feuilles fraîches, contenant des alcaloïdes, sont utilisées comme masticatoire en Arabie et en Afrique orientale.

\section{Termes ou titre militaires, certains d'origine turque ou persane}

Agha (origine turque) - officier de la cour du Sultan dans l'ancienne Turquie. Janissaire (origine turque) - soldat d'élite de l'infanterie ottomane qui appartenait à la garde du Sultan. Yatagan - sabre turc à lame recourbée vers la pointe. Goum - durant la colonisation, contingent militaire recruté en Afrique du Nord parmi les populations indigènes que l'on appelait le « Makhzen ». Moudjahidine combattant de la guerre sainte. Harki - militaire indigène d'Afrique du Nord qui servait dans une milice aux côtés des Français. Aman - en pays musulman, octroi de la vie sauve à un ennemi ou un rebelle vaincu. Chaouch - un grade à la fois militaire et administratif. Fellaga/Fellagha - partisan du soulèvement contre l'autorité française pour obtenir l'indépendance.

\section{Termes et titres religieux}

Tahar - le pur, également prénom masculin. Mufti - théoricien et interprète du droit canonique musulman, qui remplit à la fois des fonctions judiciaires et civiles. Zaouïa - établissement religieux sous l'autorité d'une confrérie musulmane, spécialement affecté à l'enseignement. Muezzin - fonctionnaire religieux musulman attaché à une mosquée et dont la fonction consiste à appeler du minaret les fidèles à la prière. Taleb - un cheikh (maître religieux selon les populations ignorantes) auquel on s'adresse pour conjurer le mauvais sort. 


\section{Termes administratifs}

Dey - ancien chef du gouvernement (d'Alger). Bey - turc : bag, seigneur, titre administratif turc. Bach - secrétaire général. Caïd - en Afrique du Nord, fonctionnaire musulman qui cumule les attributions de juge, d'administrateur, de chef de police. Djemaa - le conseil de djemaa, de Djem ou Djim : le Majestueux. Smala les équipages d'un chef arabe qui le suivent dans ses déplacements. Hadjout compagnon de l'émir. Bédouin, ine - habitant.e du désert, Arabe nomade du désert. Alim - savant. Douar - division administrative rurale en Afrique du Nord. Fellah - paysan ; petit propriétaire agricole en Afrique du Nord. Divan - salle garnie de coussins où se réunissait le Conseil du sultan (origine persane).

Termes géographiques

Kabyle, Kabylie - région montagneuse d'Algérie. Casbah - citadelle d'un souverain, dans les pays arabes, également quartier d'Alger. Oued - rivière d'Afrique du Nord, cours d'eau temporaire dans les régions arides.

\section{Mots d'origine russe}

Chapka - coiffure de fourrure à rabats pour les oreilles. Isba - petite maison en bois des paysans russes. Moujik - paysan russe, en mettant l'accent sur la force physique (les petits-enfants de Charlotte voyaient les ouvriers français comme des moujiks « en train de fendre des blocs de glace sur une Seine gelée pour éventrer ce glacier et trouver les grenouilles » (Makine 1995, 110) qui allaient être servies à l'oncle de Charlotte et à ses compagnons au Café Anglais, sur le boulevard des Italiens). Tsar - titre des empereurs de Russie. Kolkhoz - exploitation agricole collective en URSS. La Douma - conseil, assemblée dans la Russie des tsars. Boyard seigneur dans l'ancienne Russie et d'autres pays slaves. Datcha - maison de campagne russe (résidence secondaire). Koulak - paysan russe aisé à la fin du XIX et au début du XX $\mathrm{X}^{\mathrm{e}}$ siècle. Vodka - alcool de grain fabriqué en Russie. Bortsch - plat russe, potage aux choux et aux betteraves agrémenté de tomates et de viande ou de lard et lié avec de la crème fraîche. Le Kremlin - palais impérial et citadelle de Moscou. Le Bolchoï - théâtre de Moscou. Samovar - ustensile destiné à la préparation du thé, mais qui, dans le texte, acquiert une autre connotation, les habitants ayant appelé samovars des soldats mutilés, « ces soldats sans bras ni jambes, ces troncs vivants dont les yeux concentraient tout le désespoir du monde » (Makine 1995, 130). Kalachnikov - pistolet-mitrailleur d'origine soviétique. Kacha - plat russe.

Les mots russes évoqués ci-dessus, et qui abondent dans Le Testament français, même s'ils expriment les réalités purement russes ou soviétiques, n’ont 
besoin ni de traduction ni d'explication, vu qu'ils sont connus du public français/ francophone du fait de leur intégration au lexique français. En revanche, l'auteur utilise, tout en les transcrivant en français et les mettant en italiques et entre guillemets, un nombre considérable d'autres mots pour transmettre au mieux la couleur locale et toutes les spécificités de la mentalité de ses concitoyens russes, et ceux-ci acquièrent parfois d'autres connotations en fonction du contexte dans lequel ils sont utilisés. Aussi juge-t-il nécessaire de les expliquer immédiatement en français, puisque ces mots exprimant des phénomènes typiquement russes n’ont pas d'équivalent en français.

Tekhnars - « un noyau de forts en mathématiques [...] cette coterie dans laquelle on reconnaissait l'intelligentsia en herbe » (Makine 1995, 201) - ce sont donc des spécialistes des matières techniques. Fortotchka - le vasistas (ibid., 203). Frantsouz - « un Français » en russe, sobriquet donné au narrateur par ses camarades de classe. Tsvetok - au moment où il a une « révélation foudroyante [du fait qu'il est] en train de parler une langue étrangère ! [le français] », il s’interroge sur la façon différente dans les deux langues de nommer le même « reflet dans l'herbe, [le] même éclat coloré, parfumé, vivant [...] tantôt au masculin [avec] une identité crissante, fragile, cristalline imposée, semblait-il par son nom de tsvetok, tantôt au féminin [s'enveloppant] d'une aura veloutée, feutrée - devenant "une fleur" " (Makine 1995, 243-244). La Koukouchka - train avec une petite locomotive et de petits wagonnets, circulant sur une voie étroite, dont le signal ressemble à l'appel sonore d'un coucou, d'où cette onomatopée. Dessoûloir - substantif forgé par Makine à partir du verbe « dessoûler » - phénomène typiquement russe, il s'agit d'un endroit situé dans les bâtiments de la milice, où on amenait les ivrognes trouvés étendus dans les rues ou dans la neige, et où ces derniers devaient se dessoûler. Kholodets - plat de viande, porc en gelée, qui acquiert dans Le Testament français une connotation foudroyante, tout comme le samovar : les prisonniers d'un camp de concentration retrouvés en pleine taïga au fond d'un petit lac gelé onze mois sur douze, transformé en cimetière par la volonté du chef du camp, sont comparés à des morceaux de kholodets. Basmatchs - « bandits qui ne voulaient pas du pouvoir soviétique» (Makine 1995, 191). 


\section{Conclusion}

L'écriture des auteurs qui s'expriment dans une langue autre que leur langue maternelle $\mathrm{e}^{7}$ subit l'influence de leur langue d'origine à travers leur culture, qui est le sujet de prédilection de leurs textes.

De ce fait, dans l'œuvre des écrivains de langue française, nous observons la rencontre de deux mondes, de deux cultures, le français leur servant à parler de leur culture et à la mettre en dialogue avec la culture d'adoption.

Ainsi l'œuvre des trois écrivains est-elle nettement marquée par la culture de leurs pays d'origine, ce qui entraîne une cohabitation de deux cultures, un dialogue entre deux cultures, entre deux mondes.

Ce mouvement entre le français - langue d'écriture - et leur langue maternelle peut être considéré comme une opportunité dont les trois écrivains semblent profiter. À chaque fois qu'ils veulent exprimer une émotion forte dont ils veulent souligner la spécificité culturelle, ils recourent à leur langue maternelle.

En insérant dans leurs textes certains mots et expressions de leur langue maternelle ou d'un dialecte, ils expriment mieux leur culture en donnant une saveur et une certaine étrangeté à leurs textes, ce qui peut entraîner l'intérêt des lecteurs pour une autre culture. En même temps, ces mots et expressions qui transmettent les spécificités socioculturelles, et que le français n'est pas apte à reproduire, enrichissent le vocabulaire de la langue d'adoption.

En essayant de trouver des raisons à l'utilisation du français comme langue d'écriture par les écrivains non français, peut-être devrions-nous partager cette réflexion de Claire Herly qui, dans son article « Milan Kundera : un autre romancier de l'exil à la recherche de son identité », explique de la façon suivante le choix des écrivains venus de différents horizons, ou des écrivains exilés, de s'exprimer en français :

Le français permet aux écrivains exilés de langue française de se réclamer du roman européen. Kundera entend cet adjectif dans le sens husserlien : « non pas comme une détermination géographique mais “spirituelle” qui englobe aussi l’Amérique ou par exemple Israël. Ce que j'appelle le roman européen va de Cervantès à Faulkner ». Il ne s'agit pas du roman occidental car alors il oubliera la Russie. C'est un roman qui par sa naissance, par sa constitution est lié à l’Europe. (Herly 2004, 156)

L'analyse effectuée nous pousse à nous interroger sur la nécessité de réviser la définition du concept d'identité, surtout du point de vue de sa composante essen-

7 Qui, selon la définition de Jacques Derrida, est « une langue à laquelle on prête une vertu d'originalité » (Derrida 1996, 111). 
tielle qui est la culture. Au XXI ${ }^{\mathrm{e}}$ siècle, où l'ouverture des frontières et la mondialisation permettent aux gens de devenir possesseurs de différentes cultures, arrive-t-on vraiment à les fusionner ou bien, tout en s'appropriant plusieurs cultures, notre identité ne peut-elle être déterminée avant tout que par celle de notre origine ? La preuve en est l'empreinte que laisse la culture d'origine des écrivains de langue française dans leurs textes. Ce qui nous permet d'affirmer que l'exil dans une autre langue ne signifie pas forcément un exil définitif dans une autre langue et une autre culture : ce serait plutôt l'exil dans une autre langue avec sa propre culture, mise en dialogue avec la culture d'adoption tout en restant « uni en soi » (Tahar Ben Jelloun).

\section{Bibliographie}

Ben Jelloun, Tahar. Les amandiers sont morts de leurs propres blessures. Paris : Maspero/La Découverte, 1976.

Ben Jelloun, Tahar. Les yeux baissés. Paris : Le Seuil, 1991.

Calle-Gruber, Mireille. Assia Djebar. Paris : ADPF (Association pour la diffusion de la pensée française), Ministère des affaires étrangères, 2006.

Derrida, Jacques. Le monolinguisme de l'autre ou la prothèse d'origine. Paris : Galilée, 1996. Pdf téléchargeable à l'adresse <https://www.psychaanalyse.com/> (26 juillet 2018).

Djebar, Assia. L'Amour, la fantasia. Paris : Albin Michel, 1995a.

Djebar, Assia. Le Blanc de l'Algérie. Paris : Albin Michel, 1995b.

Djebar, Assia. Ces voix qui m'assiègent : en marge de ma francophonie. Paris : Albin Michel, "L'identité plurielle », 1999.

Djebar, Assia. La Disparition de la langue française. Paris : Albin Michel, 2003.

Dokhtourichvili, Mzago. "Les écrivains francophones entre langues et territoires ». Fondements historiques et ancrages culturels des langues. Julie Boissonneault, Ali Reguigui, et Mzago Dokhtourichvili (dir.). Série monographique en Sciences humaines 20. Sudbury, Ontario : 2017. 307-340.

Gauvin, Lise. L'Écriture francophone à la croisée des langues. Paris : Karthala, 1997.

Gontard, Marc. « Entretien avec Tahar Ben Jelloun ». Montray Kréyol 24 août 2008. <www. montraykreyol.org/article/entretien-avec-tahar-ben-jelloun> (17 octobre 2015).

Helmy, Lydie. «Tahar Ben Jelloun - Le conteur arabe qui écrit dans la langue de Molière ». Le Petit Journal 24 mars 2015. <www.lepetitjournal.com> (15 mai 2015).

Herly, Claire. « Milan Kundera : un autre romancier de l'exil à la recherche de son identité ». Association Européenne François Mauriac: Rencontres de la Cerisaie. Andrë̈ Makine: La Rencontre de l'Est et de l'Ouest. Margaret Parry, Marie-Louise Scheidhauer, Edward Welch (dir.). Paris : L'Harmattan, 2004. 147-162.

Knorring, Katya von. «À la recherche d’Andreï Makine, ou un humanisme de la frontière : Confession d'un porte-drapeau déchu ». Association Européenne François Mauriac : Rencontres de la Cerisaie. Andreï Makine : La Rencontre de l'Est et de l'Ouest. Margaret Parry, Marie-Louise Scheidhauer, Edward Welch (dir.). Paris : L'Harmattan, 2004. 25-35. 
Lafontant, Jean. « Langues, cultures et territoires, quels rapports? ». Cahiers Franco-canadiens de l'Ouest. Vol. 7, $\mathrm{n}^{\circ} 2$ (1995) : 227-248.

[Larousse en ligne]. Dictionnaires de français Larousse. <https://www.larousse.fr/ dictionnaires/francais/valeur/80972> (29 juillet 2018).

Makine, Andreï. Le Testament français. Paris : Mercure de France, 1995.

Makine, Andreï. La Femme qui attendait. Paris : Le Seuil, 2004.

Makine, Andreï. Cette France qu'on oublie d'aimer. Paris : Flammarion, 2006.

Nazarova, Nina. «L'Atlantide française et l'Atlantide russe d'Andreï Makine ». Association Européenne François Mauriac: Rencontres de la Cerisaie. Andreï Makine : La Rencontre de l'Est et de l'Ouest. Margaret Parry, Marie-Louise Scheidhauer, Edward Welch (dir.). Paris : L'Harmattan, 2004. 55-64.

Ozolina, Olga. «Aux prises avec un univers de fantômes : une lecture culturelle du Testament français ». Association Européenne François Mauriac : Rencontres de la Cerisaie. Andrë̈ Makine : La Rencontre de l'Est et de l'Ouest. Margaret Parry, Marie-Louise Scheidhauer, Edward Welch (dir.). Paris : L'Harmattan, 2004. 45-53.

[Unesco 1982]. Déclaration de Mexico sur les politiques culturelles. Conférence mondiale sur les politiques culturelles. Mexico, 26 juillet -6 août 1982, <https://www.bak.admin.ch/.../ definition-de-la-culture-par-l-unesco> (26 juillet 2018).

Welch, Edward. "La séduction du voyage dans Le testament français ». Association Européenne François Mauriac : Rencontres de la Cerisaie. Andreï Makine : La Rencontre de l'Est et de l'Ouest. Margaret Parry, Marie-Louise Scheidhauer, Edward Welch (dir.). Paris : L'Harmattan, 2004. 17-24.

Yefsah, Mohammed. «Entretien avec Tahar Ben Jelloun ». La Cause Littéraire. La Une CED / Les dossiers / Entretiens. 11 décembre 2011. <www.lacauselitteraire.fr/entretien-avectahar-ben-jelloun> (15 avril 2015).

Mzago Dokhtourichvili is full professor of Romance Studies and founder and director of the Research Center "Romance Intercomprehension. Intertextual dialogue". She is former head of the French Language Department at Ilia Chavchvadze State University of Language and Culture (1994-2006); and of the Georgian-European University Program - French as Foreign Language/Applied Foreign Language (2000-2010). Since 2000, she has served as the coordinator of the University Partnership Program between Ilia State University and Paul Valéry University - Montpellier 3. From 2012 to 2015, she was head of the Central and Eastern European Humanities Doctoral College - CODFREURCOR, and is currently a member of the executive committee. In 2010-2016, she represented Central and Eastern European Universities on the executive committee of AFELSH. Since 2014, she has been an editor of Études interdisciplinaires en Sciences humaines. She has been awarded three French Government medals: "Knight in Order of the Academic Palms". M. Dokhtourichvili is also an accomplished member of the 
International Association of the Order-owners. In 2011, she was named Officer of the Order of the Academic Palms. In 2019, she was named Commander of the Academic Palms. On January 29, 2018, she was elected as a Member-Correspondent of the Montpellier Science and Literature Academy, founded in 1706 by King Louis XIV. Her research interests include text linguistics, discourse analysis and didactics. She has published 26 papers in French over the last 10 years. 